\title{
VEHICLE ACCESSIBILITY: ASSOCIATION WITH NOVICE TEEN DRIVING CONDITIONS
}

Pnina Gershon ${ }^{1}$, Johnathon P. Ehsani ${ }^{2}$, Chunming Zhu ${ }^{1}$, Sheila G. Klauer ${ }^{3}$, Tom Dingus ${ }^{3}$ and Bruce Simons-Morton ${ }^{1}$

${ }^{1}$ Health Behavior Branch, Eunice Kennedy Shriver National Institute of Child Health and Human Development, National Institutes of Health, Bethesda, MD, USA

${ }^{2}$ Johns Hopkins Bloomberg School of Public Health, Baltimore, MD, USA

${ }^{3}$ Virginia Tech Transportation Institute, Blacksburg, VA, USA

Email: pnina.gershon@nih.gov,johnathon.ehsani@jhu.edu,chunming.zhu@nih.gov, CKlauer@vtti.vt.edu, tdingus@vtti.vt.edu,mortonb@exchange.nih.gov

\begin{abstract}
Summary: Novice teen drivers have disproportionally elevated crash rate compared to older drivers'. The high crash rate among novices is generally attributed to multiple risk factors, including driving inexperience, young age, risky driving behavior, vehicle accessibility, time of day, and driving with teenage passengers. The current naturalistic driving study with novice-teenagers evaluated the associations between vehicle accessibility (primary or shared) and driving conditions. Of 83 study participants 55 had primary vehicle access. Teens who shared a vehicle drove $22 \%$ more miles with an adult passenger in the vehicle compared to teens with primary vehicle access. Primary vehicle access was significantly associated with increased driving exposure (i.e. number of trips and miles driven) and driving with teen passengers. Driving with an adult present is protective, while greater exposure and driving with teenage passengers are known risk factors. Our findings indicate that primary vehicle access increases exposure overall and to driving with teen passengers, thereby increasing crash risk.
\end{abstract}

\section{INTRODUCTION}

Motor vehicle crashes are the leading cause for death among teen drivers between the ages of 15 - 20 years old. According to the National Highway Transportation Safety Administration (NHTSA), in 2014, 1,717 young drivers between the ages of 16 - 20 years old were killed in fatal crashes and 170,000 were injured. In 2014, teen drivers represented $6 \%$ of U.S. licensed drivers, yet accounted for $9 \%$ of total fatal crashes. Teen drivers also have the highest crash risk per mile driven, with the exception of the most elderly drivers (NHTSA, 2015). In 2015, compared to 2014 , there was a 10\% increase in teens' involvement in car crashes as well as a $10 \%$ increase in the number of young drivers who died in fatal crashes (NHTSA, 2016).

The disproportionally elevated crash rate of teen drivers is particularly observed during the first year of independent driving. The high crash rate is attributed to multiple risk factors, including driving inexperience, young age, risky driving behavior, vehicle accessibility, and driving conditions, including time of day and driving with teenage passengers (Shope \& Bingham, 2008; Simons-Morton et al., 2011). The more one drives the greater the crash risk, but the lower the crash rate. This is particularly observed among novices, where crash rates are at their highest early in licensure and decline rapidly with experience (Simons-Morton et al., 2015). Graduated 
Driver Licensing (GDL) and parental management programs are designed to reduce novice teens' crash risk by limiting overall driving exposure and their exposure to high-risk situations such as night driving and driving with multiple teen passengers. GDL restrictions emphasize progressive driving exposure that allows teens to gain experience gradually while they develop driving skills in relatively low-risk situations. While GDL policies have proven beneficial in reducing teens' crash risk, they do not fully address all factors related to exposure such as vehicle accessibility. Parents have the unique potential to limit overall driving exposure and exposure to higher-risk driving conditions beyond GDL limits (Gershon et al., 2016).

While crash risk increases with overall miles driven, certain driving conditions are riskier than others. For example, night driving is associated with significantly higher fatal crash risk among teen drivers compared to day driving (Rajaratnam et al., 2015; Shope \& Bingham, 2008). Even though teens' fatal nighttime driving crash rates decline gradually with time and experience, fatal crash rates are disproportionally higher among teens compared to other age groups when driving at night (McCartt \& Teoh, 2015). Klauer et al. (2011) found that teens' relative exposure to nighttime driving was significantly higher than adults' exposure which can partially explain their increased crash rates while driving at night (23\% vs $18 \%$, respectively). Adverse driving conditions including rain, snow, or fog also play an important role in teens' elevated crash risk. A survey, conducted to evaluate the critical contributors of crash occurrence, found that $4 \%$ of crashes associated with environment factors $(n=2,000)$ occurred due to either fog, rain, or snow (Singh, 2015). Using an event-triggered crash dataset, Carney et al. (2015) found that approximately $40 \%$ of teens' crashes occurred in snow/ice and about $9 \%$ occurred in wet surface conditions.

Driving with a passenger is considered to be a risk factor uniquely associated with teens' driving (Ouimet, et al., 2015). Presumably, teenage passengers increase crash risk through social influence, either pressure to increase risk or social norms that favor more risky driving (Ouimet et al., 2015). In their review paper on driving restrictions at the provisional license stage, Lin and Fearn (2003) suggested that driving with a passenger significantly increased the likelihood of teens' involvement in fatal crashes, and this risk increased with the number of teenage passengers present. Tefft et al. (2012) showed that the risk of teen drivers aged 16 - 17 years old to be in a fatal crash increased by $44 \%$ when driving with one teen passenger, doubled with the presence of two passengers, and quadrupled with three or more young passengers. Interestingly, the presence of an adult passenger, age 35 years or older, was associated with decreased teen drivers' risk of involvement in any police reported crash, as well as involvement in fatal crashes (46\% and $62 \%$, respectively). In a recent systematic review on the influence of passengers on young drivers, Ouimet et al. (2015) concluded that passenger presence increased the overall fatal crash risk of teens compared to solo driving, but the relationship between teenage passenger presence and non-fatal crash outcomes could not be confirmed. An observational study on teens' risky driving found that teen drivers were more prone to engage in risky driving behavior in the presence of teenage passengers (Simons-Morton et al., 2005). Thereby, the influence of passengers on teens' driving is not limited only to their presence or number, but also to the type of passenger.

There is a growing body of research indicating that vehicle ownership and primary vehicle accessibility are major determinants of teens' driving exposure, risky driving behavior, and crash 
risk (Gershon et al., 2016; Scott-Parker et al., 2011; Williams et al., 2006). In an analysis of the National Young Driver Survey conducted among teens from 34 states, 70\% of teen drivers reported having primary access to vehicles (Garcia-Espana et al., 2009). While providing high accessibility to a vehicle might be convenient for both parents and teens, it also results in greater vehicle accessibility for the most inexperienced and youngest drivers on the road. Garcia-Espana et al. (2009) reported that teen drivers with primary vehicle access had more than double the crash risk compared to teens who had shared access. In previous analysis of naturalistic driving data, Gershon et al. (2016) showed that primary access to a vehicle increased risky driving behavior of teens by $65 \%$.

The aim of the current study is to evaluate associations between vehicle access and novice teens' driving characteristics, such as the time of day, driving conditions, and passengers' presence. We hypothesize that primary vehicle access would result in higher driving exposure including higher miles driven and higher number of trips. We also hypothesize that primary vehicle access would be associated with higher exposure to night driving, driving on wet roads, and greater number of drives with passengers in the vehicle.

\section{METHOD}

Participants. A total of 83 newly-licensed teenage drivers (53\% females) participated in this study, with an average age of 16.48 years old $(\mathrm{SD}=.33)$. Participants were recruited from Virginia, soon after obtaining a learner's permit and were followed for up to 12 months after earning a provisional driver's license. Procedures followed an approved institutional protocol. Parental consent and teens assent were obtained.

Vehicle Instrumentation. Participant's private vehicles were installed with a Data Acquisition System (DAS) developed at the Virginia Tech Transportation Institute (Dingus et al., 2006). The DAS includes: (i) a computer to record driving kinematics data used to assess speed, threedimensional acceleration, and G-force events; (ii) Global Positioning System (GPS) to assess mileage; and (iii) video cameras to monitor the driver's face, hand, and body positioning, driver's forward and rear views, and the car dashboard. Two cameras were used to capture the vehicle interior and lap area of the rear passenger seat. Data collection and coding were conducted on the trip level and followed a rigid, systematic protocol. This approach provided a comprehensive range of trip-based data, including vehicle driving performance measures, as well as data from a battery of surveys that were periodically administrated and documented the psycho-social characteristics of the drivers. Data were collected from 2010 to 2014.

Demographic and Environmental Measures. The following factors were documented by coders who viewed the video of each trip (engine on to engine off) file for each driver: gender, road conditions (wet or dry), time of day (day or night), and passenger attributes of gender and age. Ambient light (day or night) was determined by the recorded times of sunrise and sunset of the day the trip occurred (for detailed description of the coding process see Simons-Morton et al., 2015). Before the independent driving phase started, parents completed a battery of questionnaires. Parents were asked to state whether the teen will share the vehicle with one or more additional drivers or will be the primary driver of the vehicle. The response to this question 
determined the intended vehicle accesses. Teens observed to drive $50 \%$ or more of trips taken were considered to have primary vehicle access.

\section{RESULTS}

Vehicle Accessibility. The majority of participating parents (71\%) estimated that their teens would share access to a vehicle. However, based on the actual number of trips driven by parents and teens, only $34 \%$ of the teens had a shared vehicle access. As seen in Table 1, 53\% of the parents who intended at baseline to limit vehicle accessibility eventually provided primary vehicle accessibility to the teen. In contrast, none of the parents' who intended at baseline to provide primary vehicle eventually limited the teen's accessibility.

Table 1. Parent-reported intent and actual teen vehicle accessibility during the first year of independent driving

\begin{tabular}{lccc}
\hline \multirow{2}{*}{$\begin{array}{c}\text { Intended Vehicle } \\
\text { Accessibility }\end{array}$} & \multicolumn{3}{c}{ Actual Vehicle Accessibility } \\
\cline { 2 - 4 } & $\begin{array}{r}\text { Primary } \\
\text { Access }\end{array}$ & Shared Access & Total \\
\hline Primary Access & 24 & 0 & $\mathbf{2 4}$ \\
Shared Access & 31 & 28 & $\mathbf{5 9}$ \\
\hline Total & $\mathbf{5 5}$ & $\mathbf{2 8}$ & $\mathbf{8 3}$ \\
\hline
\end{tabular}

Driving Exposure. As seen in Figure 1, vehicle accessibility was associated with the number of trips teens drove in their first year of independent driving. Teens with primary vehicle access drove significantly more trips (mean $=1062.83, \mathrm{SD}=407.63$ ) compared to teens with shared vehicle access (mean=426.82, $\mathrm{SD}=344.46), t(79)=6.96, p<.001$. The overall miles driven during the first year of independent driving was also significantly higher among those with greater vehicle access (see Figure 2). The average mile driven by teens with primary vehicle access was significantly higher (mean=7064.49, $\mathrm{SD}=3755.71)$ compared to teens with shared vehicle access (mean=3503.39, $\mathrm{SD}=2387.94), t(79)=4.56, p<.001$.

Driving Conditions. To better understand how vehicle accessibility differentiates between teens with primary and shared vehicle access, we analyzed the proportion of miles teens drove in various driving conditions. As seen in Table 2, during the evaluated period, both teens with shared and primary vehicle access drove on average less than $50 \%$ of their mileage at night. Similarly, teens with shared and primary vehicle access drove about $20 \%$ of their mileage on wet driving conditions. There was also no difference found between teens with shared or primary vehicle accessibility when driving alone or with a child. However, teens with primary vehicle access drove a significantly larger proportion of their mileage with a teen passenger $(41 \%)$ compared to teens with shared vehicle accessibility (28\%). In contrast, teens with low vehicle accessibility drove a significantly larger proportion of their mileage with an adult passenger $(34 \%)$ compared to teens with high vehicle accessibility $(12 \%)$. 


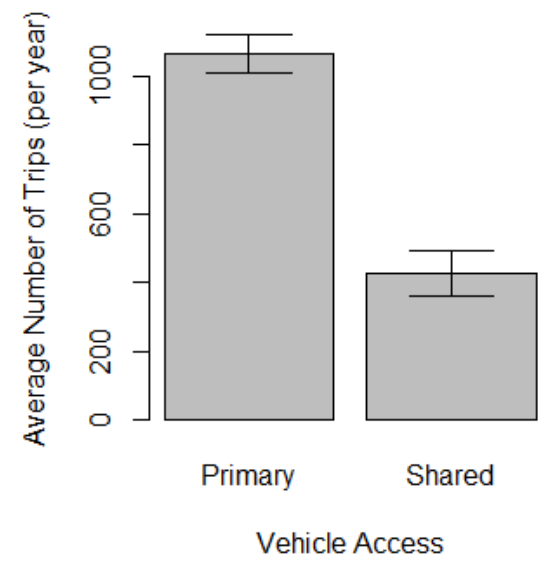

Figure 1. Average number of trips teens drove as a function of vehicle accessibility

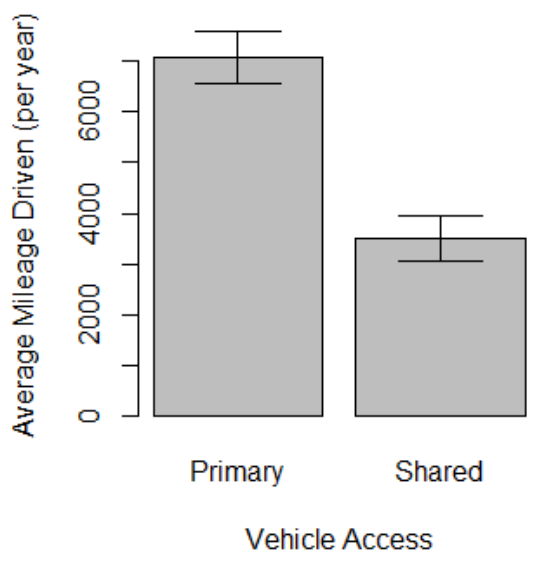

Figure 2. The total mileage teens drove as a function of vehicle accessibility

Table 2. Proportion of miles driven by teens with primary and shared vehicle access per driving condition.

\begin{tabular}{lcccr}
\hline & \multicolumn{2}{c}{ Vehicle access } & \\
\cline { 2 - 3 } Driving Conditions & Primary & Shared & $t(\mathbf{d f}), \mathbf{p}$-value \\
\hline Driving at night & 0.43 & 0.45 & $t(79)=.899, p=.371$ \\
Driving on wet roads & 0.18 & 0.22 & $t(79)=1.589, p=.116$ \\
Passenger Type & & & & \\
No Passenger & 0.42 & 0.36 & $t(79)=1.495, p=.139$ \\
Adult & 0.12 & 0.34 & $t(79)=-6.643, p<.001$ \\
Teen & 0.41 & 0.28 & $t(79)=2.895, p=.005$ \\
Child & 0.05 & 0.02 & $t(79)=1.546, p=.126$ \\
\hline
\end{tabular}

\section{DISCUSSION AND CONCLUSIONS}

Novice teen elevated crash rate is attributed to multiple risk factors. The current study used naturalistic data of teen drivers to examine associations between vehicle access and driving exposure, time of day, driving conditions, and passenger presence. The results of this study indicated that while the majority of the parents (71\%) stated at the beginning of the study that their teens' would share a vehicle, in practice, the actual number of teens who shared a vehicle was much smaller (34\%). In total, $66 \%$ of the teens in this study had primary vehicle access, a rate similar to vehicle access rate reported by Garcia-Espana et al., (2009) in survey study. Interestingly, the parents who intended to grant their teen's primary vehicle access, did so and did not curtail teen's actual vehicle accessibility regardless of their driving performance, possibly due to social considerations, practical factors, or the judgment (correctly or not) that the teen was ready for independent mobility. Further research on parents' ability to judge their teen's readiness is needed.

Teens with primary vehicle access had both higher number of trips, and higher mileage compare to teens with shared vehicle access. Driving exposure (i.e., number of trips and miles driven) is a known determinant for crash risk (Williams et al., 2006). While teens with primary and shared access drove the same proportion of time and miles at night and under inclement conditions, those with a primary vehicle drove more miles overall under these dangerous driving conditions. 
Moreover, teens with primary vehicle access were more likely to drive with a teen passenger and less likely to drive with an adult passenger. Previous studies showed that the presence of one or more teen passengers is associated with significantly higher crash risk, while driving with an adult is associated with significantly lower crash risk (Ouimet et al., 2015; Tefft et al., 2012).

Overall, teen's accessibility to a vehicle is an important factor related to exposure overall and to higher-risk driving conditions. Our findings indicated that greater accessibility to a vehicle was significantly associated with driving more with teenage passengers, which can increase crash risk, and less with parent or other adult passengers, which tends to decrease crash risk. Our findings suggest on the need for restrictions on exposure beyond GDL policies, including limiting vehicle access early in licensure that can only be accomplished through parental management of vehicle access. Furthermore, the possible benefits of parent-teen vehicle sharing, in addition to the lower risk of crash, includes creating more opportunities for parents to observe teen driving, provide additional instruction, and establish expectations for safe driving behavior. While this research links vehicle access and driving characteristics, further research is needed to assess possible association between greater vehicle access and driving performance among novice young drivers.

\section{ACKNOWLEDGMENTS}

This research was supported by the intramural program of the Eunice Kennedy Shriver National Institute of Child Health and Human Development, contract \# N01-HD-5-3405.

\section{REFERENCES}

Carney, C., McGehee, D. V., Lee, J. D., Reyes, M. L., \& Raby, M. (2010). Using an eventtriggered video intervention system to expand the supervised learning of newly licensed adolescent drivers. American Journal of Public Health, 100(6), 1101-1106.

García-España, J. F., Ginsburg, K. R., Durbin, D. R., Elliott, M. R., \& Winston, F. K. (2009). Primary access to vehicles increases risky teen driving behaviors and crashes: national perspective. Pediatrics, 124(4), 1069-1075.

Gershon, P., O’Brien, F., Zhu, C. \& Simons-Morton, B.G. (2016). Multi-Level Predictors of Teenage Risky Driving. Young Driver Subcommittee Midyear Meeting, Transportation Research Board.

Klauer, S. G., Simons-Morton, B., Lee, S. E., Ouimet, M. C., Howard, E. H., \& Dingus, T. A. (2011). Novice drivers' exposure to known risk factors during the first 18 months of licensure: the effect of vehicle ownership. Traffic injury prevention, 12(2), 159-168.

Lin, M. L., \& Fearn, K. T. (2003). The provisional license: nighttime and passenger restrictions a literature review. Journal of Safety Research, 34(1), 51-61.

McCartt, A. T., \& Teoh, E. R. (2015). Type, size and age of vehicles driven by teenage drivers killed in crashes during 2008-2012. Injury prevention, 21(2), 133-136.

National Highway Traffic Safety Administration (NHTSA) (2015), Dept. of Transportation (US). Traffic Safety Facts 2013: Young Drivers. Washington (DC): NHTSA - See more at: http://www.teendriversource.org/stats/support teens/detail/57\#sthash.mtdcXb1V.dpuf 
National Highway Traffic Safety Administration. (2016). 2015 motor vehicle crashes: overview. Traffic safety facts research note, 2016, 1-9.

Rajaratnam, S. M., Landrigan, C. P., Wang, W., Kaprielian, R., Moore, R. T., \& Czeisler, C. A. (2015). Teen crashes declined after Massachusetts raised penalties for graduated licensing law restricting night driving. Health Affairs, 34(6), 963-970.

Ouimet, M. C., Pradhan, A. K., Brooks-Russell, A., Ehsani, J. P., Berbiche, D., \& SimonsMorton, B. G. (2015). Young drivers and their passengers: a systematic review of epidemiological studies on crash risk. Journal of Adolescent Health, 57(1), S24-S35.

Scott-Parker, B., Watson, B., King, M. J., \& Hyde, M. K. (2011). Mileage, car ownership, experience of punishment avoidance, and the risky driving of young drivers. Traffic injury prevention, $12(6), 559-567$.

Shope, J. T., \& Bingham, C. R. (2008). Teen driving: motor-vehicle crashes and factors that contribute. American Journal of Preventive Medicine, 35(3), S261-S271.

Simons-Morton, B. G., Hartos, J. L., \& Beck, K. H. (2003). Persistence of effects of a brief intervention on parental restrictions of teen driving privileges. Injury Prevention, 9(2), 142146.

Simons-Morton, B., Lerner, N., \& Singer, J. (2005). The observed effects of teenage passengers on the risky driving behavior of teenage drivers. Accident Analysis \& Prevention, 37(6), 973982.

Simons-Morton, B., \& Ouimet, M. C. (2006). Parent involvement in novice teen driving: a review of the literature. Injury Prevention, 12(1), i30-i37.

Simons-Morton, B. G., Ouimet, M. C., Zhang, Z., Klauer, S. E., Lee, S. E., Wang, J., \& Dingus, T. A. (2011). The effect of passengers and risk-taking friends on risky driving and crashes/near crashes among novice teenagers. Journal of Adolescent Health, 49(6), 587-593.

Simons-Morton, B. G., Klauer, S. G., Ouimet, M. C., Guo, F., Albert, P. S., Lee, S. E., Ehsani, J. P., Pradhan, A. K., \& Dingus, T. A. (2015). Naturalistic teenage driving study: findings and lessons learned. Journal of Safety Research, 54, 41-44.

Singh, S. (2015). Critical Reasons for Crashes Investigated in the National Motor Vehicle Crash Causation Survey (No. DOT HS 812 115).

Tefft, B. C., Williams, A. F., \& Grabowski, J. G. (2013). Teen driver risk in relation to age and number of passengers, United States, 2007-2010. Traffic injury prevention, 14(3), 283-292.

Williams, A. F., Leaf, W. A., Simons-Morton, B. G., \& Hartos, J. L. (2006). Vehicles driven by teenagers in their first year of licensure. Traffic injury prevention, 7(1), 23-30. 